ISSN 0258-7122 (Print), 2408-8293 (Online)

Bangladesh J. Agril. Res. 41(1): 151-162, March 2016

\title{
EFFECT OF FLOODING ON GROWTH AND YIELD OF MUNGBEAN GENOTYPES
}

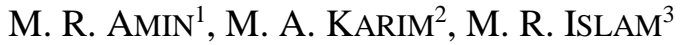 \\ S. AKTAR ${ }^{4}$ AND M. A. HOSSAIN ${ }^{5}$
}

\begin{abstract}
The field experiment was carried out with some selected mungbean genotypes viz. IPSA-13, VC-6173A, BU mug 2, BARI Mung-5 and IPSA-12 to observe the effect of 4-days flooding on their growth and yield of mungbean under field conditions at Bangabandhu Sheikh Mujibur Rahman Agricultural University, Gazipur, Bangladesh during September to November, 2011 maintaining 3-5 cm standing water at 24 days after emergence. Days to flowering and maturity delayed in flooded plants over control depending on the genotypes. Flooding significantly reduced Total Day Matters (TDM), number of pods per plant, seed size and seed yield of the mungbean genotypes over control. Considering higher seed yield, larger seed size and less yield reduction relative to control VC-6173A, BU mug 2 and IPSA-13 were found tolerant to soil flooding condition.
\end{abstract}

Keywords: Soil flooding, growth and yield, mungbean genotypes.

\section{Introduction}

In tropical and subtropical region, heavy rainfall in the rainy season frequently induces short-term flooding in crop fields. Soil flooding occurs over a vast regions throughout the world (Kozlowski, 1984) adversely affecting approximately 10\% of the global land area (FAO, 2002). Inundation of land for a long period is harmful even for wetland crops, especially if the standing water is stagnant. Soil flooding has long been identified as a major abiotic stress and the constraints it imposes on roots have marked effects on plant growth and development (Parent et al., 2008). Flooding restricts aeration of the soil creating an oxygen-free environment in the root zone. Under this condition, crops cultivated are damaged to various degrees resulting in poor growth and low yield. Thus soil flooding is a significant agronomic problem for crop production (Carter et al., 1990).

Mungbean is widely cultivated in the tropical and subtropical regions of the world. The crop is sometimes subjected to the detrimental effect of flooding. Mungbean cannot withstand soil flooding, particularly during the early stages of growth (Singh and Singh, 2011). Since this crop is highly susceptible to flooding damage, soil flooding is considered as one of the major factors that restrict the productivity

${ }^{1}$ Senior Scientific Officer, OFRD, Bangladesh Agricultural Research Institute (BARI), Gazipur-1701, ${ }^{2 \& 3}$ Professor, Department of Agronomy, Bangabandhu Sheikh Mujibur Rahman Agricultural University (BSMRAU), Gazipur-1706, ${ }^{4}$ Scientific Officer, Pulse Research sub-station, BARI, Gazipur-1701, ${ }^{5}$ Principal Scientific Officer, Pulse Research sub-station, BARI, Gazipur-1701, Bangladesh. 
of this crop. A high monsoon rain at the time of reproductive period caused enormous loss of both seed yield and seed quality of mungbean (Williams et al., 1995). The extent of responses of crop plants to flooding is controlled mainly by plant genetic factors and is influenced by environmental conditions as well. The aspects concerning the agronomic responses of mungbean to soil flooding are important, as (Nawata, 1989) reported that under actual field conditions most of the crops experienced only transient or short-term soil flooding.

Some earlier experiments indicated that varietal differences in tolerance to soil flooding were existed in mungbean (Hamid et al., 1991). Genotypic difference of mungbean plants to short-term soil flooding was also reported by Islam (2005). However, those experiments were conducted mostly under semi-controlled conditions. The findings of those studies may or may not reflect that of the actual field conditions. Therefore, the experiment was designed to find out the effect of soil flooding under field conditions at pre-flowering stage on the growth and yield of some selected mungbean genotypes.

\section{Materials and Method}

The experiment was conducted in the field of the Department of Agronomy of Bangabandhu Sheikh Mujibur Rahman Agricultural University, Gazipur, Bangladesh during 8 September, 2011 to 15 November, 2011. Five mungbean genotypes viz. IPSA-13, VC-6173A, BU mug 2, BARI Mung-5 and IPSA-12 were tested under this study. The genotypes were flooded with $3-5 \mathrm{~cm}$ of standing water for 4 days (96 hours) at pre-flowering stage from 24-27 days after emergence (DAE).

The experiment was laid out in a split-plot design with three replications. Flooding treatments were placed in the main-plots and mungbean genotypes were in the subplots. The size of each main plot was $8 \mathrm{~m} \times 2 \mathrm{~m}=16 \mathrm{~m}^{2}$ and the size of each subplot was $(2 \mathrm{~m} \times 1.5 \mathrm{~m})$. Drain in between two main plots was $1.5 \mathrm{~m}$ so that flooded water cannot soak to the neighboring experimental plots. Each sub-plot had 5 rows of mungbean genotype with a spacing of $30 \mathrm{~cm} \times 10 \mathrm{~cm}$. At the border of each plot respective mungbean genotype was grown to avoid border effect.

The experimental land was ploughed properly and at the time of first ploughing cowdung @ $10 \mathrm{t} / \mathrm{ha}$ was applied. A blanket dose of fertilizers $20-20-30 \mathrm{~kg} / \mathrm{ha}$ of N-P-K was applied and thoroughly incorporated into the soil of each plot at the time of final land preparation. Seeds of uniform size and shape of five mungbean genotypes were sorted from their stock and treated with Vitavex 200 @ 3 g per kg seed before sowing. The seeds were soaked in water for 4 hours before sowing and imbibed seeds were selected for sowing. Most seedlings emerged within 3 days of sowing. Seedlings were thinned out after one week of emergence keeping healthy seedlings of uniform growth. During growing period the average maximum and 
minimum temperature ranged were between $30.43^{\circ} \mathrm{C}$ and $25.30^{\circ} \mathrm{C}$, respectively. The total rainfall during experimentation period was $186.60 \mathrm{~mm}$. Seedlings were raised at optimal soil moisture condition (about 50\% AWC). The insecticide Karate at the rate of $2.0 \mathrm{ml}$ per litre water was sprayed to protect the plants from thrips and aphids. Other management practices were done adequately to maintain normal growth of seedlings.

Two treatments were imposed on the growing seedlings in separate experimental plots. Among 6 experimental plots, 3 main-plots were maintained as non-flooded (control) and the rest 3 plots were flooded. Treatments were randomly placed in the experimental units. When the seedlings were 24 days old, flooding with $3-5 \mathrm{~cm}$ of standing water was maintained continuously for 4 days (96 hours) during 24-27 DAE. At the same time the optimal soil moisture (about 50\% AWC) was maintained as control treatment. Normal irrigation was given to the control plots for establishment of the crops. Data were collected from the beginning of the flood treatment and five plants from each plot of each genotype were pulled out for destructive sampling to determine the dry weight of different plant parts every 10 days interval. After harvesting, the seedlings of both waterlogged and control experiments were segmented into components i.e. stem, leaf, petiole, and reproductive organs. The segmented parts were then oven dried at $80^{\circ} \mathrm{C}$ for 72 hours to a constant weight and dry weights were taken separately. Total dry weight (DW) was calculated by summing up the dry weights of stem, leaf, petiole, and reproductive parts of plants. Dates of flowering and maturity were recorded based on the visual observation. When about $50 \%$ plants bloomed was considered as first $50 \%$ flowering and when about $80 \%$ pods matured was considered as maturity stage. Yield and yield components were recorded from the harvested sample at maturity. All data were analysed statistically and mean separation was done using LSD at $5 \%$ level.

\section{Results and Discussion}

\section{Days to $50 \%$ flowering and days to maturity}

Irrespective of genotypes, 4-days flooding delayed days to $50 \%$ flowering by 3 days than that of non-flooded control. Across the genotypes they were however, statistically non-significant. The shortest duration to $50 \%$ flowering was required in BU mug 2 (34 days) followed by BARI Mung-5 (35 days) and VC-6173A (36 days). IPSA-13 and IPSA-12 took 37.00 and 37.83 days to $50 \%$ flowering, respectively (Table 1 ).

Genotype-treatment interaction on days to maturity was significant (Table 2). Soil flooding for 4 days significantly delayed days to maturity. Days to maturity in control plants ranged from 55 to 59 days and BU mug 2 and BARI Mung 5 both took 55 days to mature. IPSA-12 and VC-6173A took 57 and 58 days, respectively 
to mature and the longest duration was 59 days in IPSA-13. On the other hand, days to maturity in flooded plants ranged from 59 to 66 days where maturity delayed by 4 days in VC-6173A (63 days), BU mug 2 (59 days), BARI Mung-5 (59 days) and IPSA-12 (61 days).Whereas, IPSA-13 (66 days) took 7 more days to mature than that of control. Similarly Kumar et al. (2013) reported that both tolerant and sensitive mungbean genotypes showed the inhibition of flowering and pod setting under waterlogging.

Table 1. Effect of 4-days flooding on days to $50 \%$ flowering of 5 selected mungbean genotypes

\begin{tabular}{l|c|l|c}
\hline \multicolumn{1}{c|}{ Treatment } & $\begin{array}{c}\text { Days to 50\% } \\
\text { flowering }\end{array}$ & \multicolumn{1}{|c|}{ Genotype } & $\begin{array}{c}\text { Days to 50\% flowering } \\
\text { under flooding condition }\end{array}$ \\
\hline Control & 34.40 & IPSA-13 & $37(3)$ \\
Flooding (4 days) & $37.46(3)$ & VC-6173A & $35(1)$ \\
& & BU mug 2 & $34(0)$ \\
& & BARI Mung-5 & $35(1)$ \\
& & IPSA-12 & $37(3)$ \\
\hline LSD 0.05 & NS & LSD ${ }_{0.05}$ & 0.83 \\
CV $(\%)$ & 1.88 & CV $(\%)$ & 1.88 \\
\hline
\end{tabular}

Figures in parenthesis indicate delay in days to flowering over control.

Table 2. Effect of 4-days flooding on days to maturity of 5 selected mungbean genotypes

\begin{tabular}{l|cc|c}
\hline \multirow{2}{*}{ Genotypes } & \multicolumn{2}{|c|}{ Days to maturity } & \multirow{2}{*}{$\begin{array}{c}\text { Delay in days to maturity } \\
\text { over the control }\end{array}$} \\
\cline { 2 - 3 } & Control & 4-days flooding & 7 \\
\hline IPSA-13 & 59 & 66 & 5 \\
VC-6173A & 58 & 63 & 4 \\
BU mug 2 & 55 & 59 & 4 \\
BARI mung 5 & 55 & 59 & 4 \\
IPSA-12 & 57 & 61 & \\
\hline LSD & & 0.88 & \\
CV (\%) & & 0.82 & \\
\hline
\end{tabular}

\section{Plant height}

Plant height of flooded mungbean genotypes increased progressively from vegetative stage to maturity (Fig. 1). Among the genotypes, plant height varied significantly at all the growth stages except vegetative stage $(0$ day after termination of flooding). During 10 days recovery period (10 days), plant height of IPSA-13 $(30.49 \mathrm{~cm})$ was the highest though other genotypes did not differ significantly and were almost uniform when excess soil moisture was removed. 
Plant height at later stages of growth varied among the genotypes. The increment in plant height of some genotypes at later stages of growth indicated the greater recovery ability. Voesenek and Blom (1996) stated that the elongation of stems and petioles may enable plants to emerge from the water in aquatic and flooding tolerant terrestrial species. At 20 days after termination of flooding, the tallest plant was found in VC-6173A $(33.93 \mathrm{~cm})$ but other genotypes had statistically similar height while, BU mug $2(29.12 \mathrm{~cm})$ was the shortest. At maturity (30 DTF), the tallest plant was recorded in IPSA-12 $(40.68 \mathrm{~cm})$ followed by VC-6173A $(38.60$ $\mathrm{cm})$ and BARI Mung-5 $(36.87 \mathrm{~cm})$. The lowest height was recorded in BU mug 2 $(34.37 \mathrm{~cm})$.

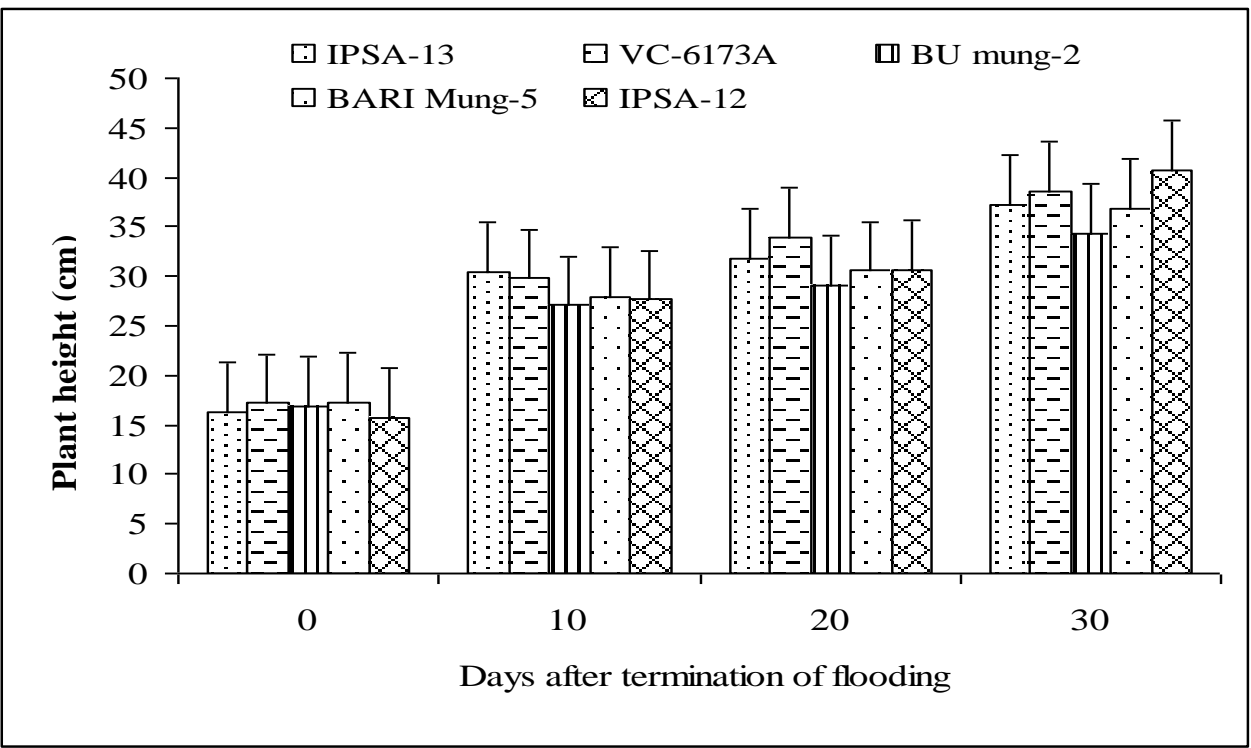

Fig.1. Effect of 4-days soil flooding on plant height of 5 mungbean genotypes.

\section{Number of leaves plant ${ }^{-1}$}

Soil flooding and genotypes interacted significantly on the number of leaves plant ${ }^{1}$ during 10 days recovery period (10 days after termination of flooding (DTF) but it was non-significant at 0,20 and 30 days after termination of flooding (Table 3). Control treatment produced higher number of leaves plant ${ }^{-1}$ than those of 4-days flooded plants. The number of leaves plant ${ }^{-1}$ in control plants increased considerably and ranged from 5.00 to 5.60 in control plants and 3.80 to 4.55 in flooded plants. At later stages of growth (20 and $30 \mathrm{DTF})$, the soil floodinggenotype interaction effect on the number of leaves plant ${ }^{-1}$ was non-significant but small scale genotypic differences were observed. Leaf production plant $^{-1}$ is a varietal character of mungbean as reported by Saha (2005). Nawata (1989) observed that short-term flooding did not affect the changes of the number of leaves in all the varieties of yard long bean. 
Table 3. Effect of 4-day soil flooding on number of leaves plant ${ }^{-1}$ of 5 selected mungbean genotypes at 10 days after termination of flooding (DTF)

\begin{tabular}{l|cc}
\hline \multirow{2}{*}{ Genotypes } & \multicolumn{2}{|c}{ Number of leaves plant $^{-1}$} \\
\cline { 2 - 3 } & Control (Mean \pm SD) & 4-day flooding (Mean \pm SD) \\
\hline IPSA-13 & $5.07 \pm 0.12$ & $4.33 \pm 0.31$ \\
VC-6173A & $5.60 \pm 0.20$ & $4.53 \pm 0.31$ \\
BU mug 2 & $5.40 \pm 0.20$ & $3.80 \pm 0.35$ \\
BARI Mung-5 & $5.00 \pm 0.00$ & $4.07 \pm 0.31$ \\
IPSA-12 & $5.13 \pm 0.23$ & $4.50 \pm 0.10$ \\
\hline LSD 0.05 & \multicolumn{3}{|c}{0.405} \\
CV (\%) & 4.94 \\
\hline
\end{tabular}

$\mathrm{SD}=$ Standard Deviation

\section{Leaf area plant ${ }^{-1}$}

The soil flooding-genotype interaction on leaf area plant ${ }^{-1}$ was found significant at all the growth stages of mungbean (Table 4). Control treatment produced the higher leaf area plant ${ }^{-1}$ than those of flooded plants after termination of flooding $(0$ DTF). The highest leaf area plant ${ }^{-1}$ was produced by IPSA-13 $\left(307.18 \mathrm{~cm}^{2}\right.$ plant $\left.^{-1}\right)$ followed by VC-6173A $\left(192.76 \mathrm{~cm}^{2}\right.$ plant $\left.\left.^{-1}\right)\right)$, BU mug $2\left(179.17 \mathrm{~cm}^{2}\right.$ plant $\left.^{-1}\right)$ and IPSA-12 $\left(220.07 \mathrm{~cm}^{2}\right.$ plant $\left.^{-1}\right)$. The lowest leaf area plant ${ }^{-1}$ was obtained by BARI Mug-5 $\left(150.19 \mathrm{~cm}^{2}\right.$ plant $\left.^{-1}\right)$. Leaf area was reduced significantly when plants were flooded for 4 days. The reduction in leaf area relative to control was $49.4 \%$ in IPSA-12 followed by IPSA-13 $(62.8 \%)$ and the lowest was in BARI Mung-5 $(86.6 \%)$. Leaf area plant $^{-1}$ of flooded plants increased to some extent during the recovery period (10 DTF). Under the non-flooded control condition VC-6173A produced the highest leaf area $\left(365.51 \mathrm{~cm}^{2}\right.$ plant $\left.^{-1}\right)$ followed by IPSA-13 $(300.58$ $\mathrm{cm}^{2}$ plant $\left.{ }^{-1}\right)$, but leaf area of IPSA-12 (319.62 $\mathrm{cm}^{2}$ plant $\left.^{-1}\right)$ and BARI Mung-5 $\left(317.67 \mathrm{~cm}^{2}\right.$ plant $\left.{ }^{-1}\right)$ did not differ significantly. The lowest leaf area $\left(283.9 \mathrm{~cm}^{2}\right.$ plant $^{-1}$ ) was produced by BU mug 2. Leaf area plant ${ }^{-1}$ of all the flooded genotypes were reduced by $50 \%$ relative to control. Umaharan et al. (1997) reported that leaf area development during the vegetative phase showed significant differences between flooded and control in cowpea plants. At 20 days after termination of flooding, leaf area plant ${ }^{-1}$ of control plants were statistically higher than those of flooded plants except in BU mung-2 $\left(284.10 \mathrm{~cm}^{2}\right.$ plant $\left.{ }^{-1}\right)$ and IPSA-12 $\left(315.18 \mathrm{~cm}^{2}\right.$ plant $\left.^{-1}\right)$. The leaf area of VC-6173A and BARI Mung-5 were 480.20 and 436.30 $\mathrm{cm}^{2}$ plant $^{-1}$, respectively. At maturity (30 DTF), the leaf area plant ${ }^{-1}$ of both control and flooded plants were lower than those of leaf area produced during preflowering (0 DTF) or pod filling stage (20 DTF). This might be due to the senescence and abscission of lower leaves at maturity. Similar result was also observed by Islam (2003). 
Table 4. Effect of 4-days flooding on leaf area plant ${ }^{-1}$ of 5 selected mungbean genotypes

\begin{tabular}{|c|c|c|c|c|c|c|c|c|}
\hline \multirow{3}{*}{ Genotypes } & \multicolumn{8}{|c|}{ Leaf area plant ${ }^{-1}$} \\
\hline & \multicolumn{2}{|c|}{$0 \mathrm{DTF}$} & \multicolumn{2}{|c|}{$10 \mathrm{DTF}$} & \multicolumn{2}{|c|}{$20 \mathrm{DTF}$} & \multicolumn{2}{|c|}{$30 \mathrm{DTF}$} \\
\hline & Control & Flooded & Control & Flooded & Control & Flooded & Control & Flooded \\
\hline IPSA-13 & 307.18 & 192.84 & 300.58 & 157.74 & 323.4 & 215.4 & 200.30 & 105.30 \\
\hline VC-6173A & 192.76 & 129.61 & 365.51 & 159.48 & 480.2 & 213.2 & 161.20 & 124.60 \\
\hline BU mug 2 & 179.17 & 112.9 & 283.9 & 129.63 & 284.1 & 237.7 & 140.80 & 102.60 \\
\hline BARI Mung- 5 & 150.19 & 130.02 & 317.67 & 146.81 & 436.3 & 196.7 & 145.20 & 105.10 \\
\hline IPSA-12 & 220.07 & 108.75 & 319.62 & 137.47 & 315.18 & 232.70 & 164.40 & 100.80 \\
\hline $\operatorname{LSD}_{0.05}$ & \multicolumn{2}{|c|}{42.78} & \multicolumn{2}{|c|}{28.69} & \multicolumn{2}{|c|}{48.90} & \multicolumn{2}{|c|}{23.18} \\
\hline $\mathrm{CV}(\%)$ & \multicolumn{2}{|c|}{15.22} & \multicolumn{2}{|c|}{9.87} & \multicolumn{2}{|c|}{9.63} & \multicolumn{2}{|c|}{9.92} \\
\hline
\end{tabular}

$\mathrm{DTF}=$ days after termination of flooding.

\section{Total dry matter}

The control treatment had the higher total dry matter (TDM) than that of 4 days flooded plants although genotypic variation existed (Table 5). After termination of flooding, IPSA-13 grown under control produced the highest TDM but other genotypes did not vary significantly. Similar trend was also observed during 10 days recovery period (10 DTF) and also at pod filling stage (20 DTF). At maturity, control treatment produced the highest TDM by BARI Mung-5 (7.45 g plant $\left.^{-1}\right)$ followed by IPSA-13 $\left(7.23 \mathrm{~g} \mathrm{plant}^{-1}\right)$. The lowest TDM was produced by IPSA-12 (5.61 $\left.\mathrm{g} \mathrm{plant}^{-1}\right)$. TDM obtained in flooded plants of mungbean genotypes did not vary significantly except $\mathrm{VC}-6173 \mathrm{~A}$. The rate of reduction relative to control was about 50\% after termination of flooding (0 DTF), whereas TDM reduced during the recovery period (10 DTF) ranged from 42.6 to $23.9 \%$ in different genotypes. Minchin et al. (1978) observed severe reduction in biomass (50\% of the control) when cowpea plants were flooded in a similar fashion during vegetative phase. Kumar et al. (2013) reported that soil flooding in mungbean reduced total dry matter production and also affected the dry matter partitioning. TDM at pod filling stage (20 DTF) increased to a considerable extent than that of TDM gained during the recovery period (10 DTF) and the value was 62.4 to $45.3 \%$ relative to control. $\mathrm{VC}-6173 \mathrm{~A}$ and $\mathrm{BU}$ mug 2 had the lowest rate of reduction relative to control $62.4 \%$ and $61.2 \%$, respectively. At maturity (30 DTF), TDM of flooded plants reduced to a great extent ranged from $42.3 \%$ to $26.6 \%$. This might be due to the reduction of leaf dry weight as caused by senescence and abscission of lower leaves at maturity. At maturity, the rate of reduction in TDM ranged from $42.3 \%$ to $26.6 \%$, VC-6173A being the lowest and BARI Mung-5 the highest which was statistically similar to those of IPSA-13 (29.6\%), BU mug 2 (37.3\%) and IPSA-12 $(39.8 \%)$. 
Table 5. Effect of 4-days flooding on total dry matter of 5 selected mungbean genotypes

\begin{tabular}{|c|c|c|c|c|c|c|c|c|}
\hline \multirow[t]{3}{*}{ Genotypes } & \multicolumn{8}{|c|}{ Total dry matter $\left(\mathrm{g} \mathrm{plant}^{-1}\right)$} \\
\hline & \multicolumn{2}{|c|}{0 DTF } & \multicolumn{2}{|c|}{$10 \mathrm{DTF}$} & \multicolumn{2}{|c|}{$20 \mathrm{DTF}$} & \multicolumn{2}{|c|}{$30 \mathrm{DTF}$} \\
\hline & Control & Flood & Control & Flood & Control & Flood & Control & Flood \\
\hline IPSA-13 & 2.00 & 0.49 & 3.12 & 1.33 & 6.00 & 2.46 & 7.23 & 2.14 \\
\hline VC-6173A & 1.50 & 0.63 & 3.43 & 1.35 & 5.16 & 3.11 & 7.02 & 2.97 \\
\hline BU mug 2 & 1.43 & 0.55 & 3.68 & 0.88 & 4.38 & 2.42 & 6.07 & 2.25 \\
\hline $\begin{array}{l}\text { BARI } \\
\text { Mung- } 5\end{array}$ & 1.43 & 0.51 & 3.41 & 1.04 & 4.88 & 2.01 & 7.45 & 1.98 \\
\hline IPSA-12 & 1.39 & 0.53 & 3.38 & 0.77 & 4.83 & 2.35 & 5.61 & 2.23 \\
\hline $\operatorname{LSD}_{0.05}$ & 1.4 & & 0.2 & & 0.2 & & 0.3 & \\
\hline $\mathrm{CV}(\%)$ & 8.1 & & 6.4 & & 4.2 & & 4.6 & \\
\hline
\end{tabular}

$\mathrm{DTF}=$ days after termination of flooding

\section{Yield and yield components}

Yield and yield characters of mungbean genotypes varied significantly due to the influence of 4-days soil flooding. Soil flooding-genotype interacted significantly on pod plant ${ }^{-1}, 1000$-seeds weight and seed yield $\left(\mathrm{g} \mathrm{plant}^{-1}\right)$ but non-significant on other yield contributing characters (Table 6). Under control condition, the highest number of pods plant ${ }^{-1}$ was produced by IPSA-12 (11.50) which was statistically similar to IPSA-13 (11.30). BARI Mung-5 (9.80) and BU mug 2 (9.40) while VC$6173 \mathrm{~A}$ produced the least (9.00). Soil flooding for 4 days significantly reduced the number of pods plant ${ }^{-1}$ irrespective of genotypes. Similar result was also observed in legumes by Suleiman et al., (2007), Pociecha et al. (2008) and Celik and Turhan (2011) under flooding condition. The higher rate of reduction in pods plant $^{-1}$ over the control was in the genotypes IPSA-13 (54.9\%) and IPSA-12 (55.7\%). The rate of reduction in BARI Mung-5, BU mug 2 and VC-6173A was $63.6 \%, 73.4 \%$ and $76.7 \%$, respectively.

Table 6. Effect of 4-days flooding on pod plant ${ }^{-1}$ of mungbean genotypes

\begin{tabular}{l|c|c|c}
\hline \multirow{2}{*}{ Genotypes } & \multicolumn{2}{|c|}{ Pod plant $^{-1}$} & \multirow{2}{*}{$\begin{array}{c}\text { of reduction rate } \\
\text { over control }\end{array}$} \\
\cline { 2 - 3 } & Control & 4-days soil flooding & 54.9 \\
IPSA-13 & 11.30 & 6.20 & 76.7 \\
VC-6173A & 9.00 & 6.90 & 73.4 \\
BU mug 2 & 9.40 & 6.90 & 63.6 \\
BARI Mung-5 & 9.80 & 6.23 & 55.7 \\
IPSA-12 & 11.50 & 6.40 & \\
\hline LSD 0.05 & \multicolumn{3}{|}{0.70} \\
CV $(\%)$ & 4.88 \\
\hline
\end{tabular}

DTF=days after termination of flooding 
The interaction effect of mungbean genotypes and 4-days soil flooding on 1000seed weight was statistically significant (Table 7). Plants grown under non-flooded control treatment had the larger seed size than those of 4-days soil flooded plants. One thousand seed weight of IPSA-13 was the highest $(57.47 \mathrm{~g})$ while the lowest was in IPSA-12 (37.50 g). Other genotypes viz. VC-6173A (46.25 g), BU mug 2 (46.70 g) and BARI Mung-5 (44.75 g) were statistically similar in 1000-seed weight. Across the genotypes, seed size in flooded plants ranged from 55.4 to 34.2g. 1000-seed weight in flooded plants reduced to different extent over the control where in the genotype IPSA-13 $(96.4 \%)$ was less affected followed by IPSA-12 (91.2\%) and VC-6173A (92\%). Seed size of BARI Mung-5 and BU mug 2 reduced by $88.6 \%$ and $85.9 \%$, respectively relative to control.

Table 7. Effect of 4-days flooding on 1000-seeds weight of mungbean genotypes

\begin{tabular}{l|c|c|c}
\hline \multirow{2}{*}{ Genotypes } & \multicolumn{2}{|c|}{ 1000-seed weight (g) } & \\
\cline { 2 - 4 } & $\begin{array}{c}\text { Control } \\
\text { (Mean } \pm \text { SD) }\end{array}$ & $\begin{array}{c}\text { 4-days soil } \\
\text { flooding } \\
\text { (Mean } \pm \text { SD) }\end{array}$ & $\begin{array}{c}\text { \% of reduction rate over } \\
\text { control }\end{array}$ \\
\hline IPSA-13 & $57.47 \pm 0.87$ & $55.40 \pm 1.35$ & 96.4 \\
VC-6173A & $46.25 \pm 2.55$ & $42.55 \pm 1.95$ & 92.0 \\
BU mug 2 & $46.70 \pm 0.70$ & $40.10 \pm 1.18$ & 85.9 \\
BARI Mung-5 & $44.75 \pm 0.55$ & $39.63 \pm 0.21$ & 88.6 \\
IPSA-12 & $37.50 \pm 0.96$ & $34.20 \pm 0.92$ & 91.2 \\
\hline LSD 0.05 & \multicolumn{3}{|c}{2.135} \\
CV (\%) & \multicolumn{3}{c}{2.78} \\
\hline
\end{tabular}

$\mathrm{SD}=$ Standard Deviation

Table 8. Effect of 4-days flooding on the seed yield of mungbean genotypes

\begin{tabular}{l|cc|c}
\hline \multirow{2}{*}{ Genotypes } & \multicolumn{2}{|c|}{ Seed yield $\left(\mathrm{g} \mathrm{plant}^{-1}\right)$} & \multirow{2}{*}{$\begin{array}{c}\text { \% of reduction rate } \\
\text { over control }\end{array}$} \\
\cline { 2 - 3 } & $\begin{array}{c}\text { Control } \\
\text { (Mean } \pm \mathrm{SD})\end{array}$ & 4-days soil floodings & \\
\hline IPSA-13 & $4.81 \pm 0.11$ & $2.40 \pm 0.29$ & 50.0 \\
VC-6173A & $4.04 \pm 0.72$ & $2.99 \pm 0.40$ & 75.0 \\
BU mug 2 & $3.79 \pm 0.57$ & $2.46 \pm 0.34$ & 65.0 \\
BARI Mung-5 & $3.95 \pm 0.34$ & $1.96 \pm 0.40$ & 50.0 \\
IPSA-12 & $3.79 \pm 0.48$ & $2.16 \pm 0.52$ & 57.0 \\
\hline LSD 0.05 & \multicolumn{3}{|c}{0.375} \\
CV $(\%)$ & 6.73 \\
\hline
\end{tabular}

$\mathrm{SD}=$ Standard Deviation 
Seed yield of mungbean genotypes ranged from 3.79 to $4.81 \mathrm{~g}$ plant $^{-1}$ in nonflooded control plot (Table 8). IPSA-13 produced the highest seed yield (4.81g plant $^{-1}$ ) but seed yield of other genotypes did not vary significantly viz. VC-6173A (4.04 g plant $^{-1}$ ), BARI Mung-5 (3.95 g plant $\left.^{-1}\right)$, BU mug 2 and IPSA-12 both 3.79 $\mathrm{g}$ plant $^{-1}$ in control treatment. Seed yield in flooded plants ranged from $1.96 \mathrm{~g}$ to $2.99 \mathrm{~g}^{-1}$ plant $^{-1}$ and reduced at different degrees depending on the genotypes. From the Table 8 , it was observed that $50 \%$ reduction in seed yield relative to control was both in IPSA-13 and BARI Mung-5. Seed yield was reduced by $57 \%$ in IPSA$12,65 \%$ in BU mug 2 and the lowest was in VC-6173A (75\%). This indicated that VC-6173A was least affected by 4-days flooding in respect of seed yield. Total dry matter production and seed yield of flooded plants showed linear association and seed yield increased with the increment of TDM (Fig. 2).

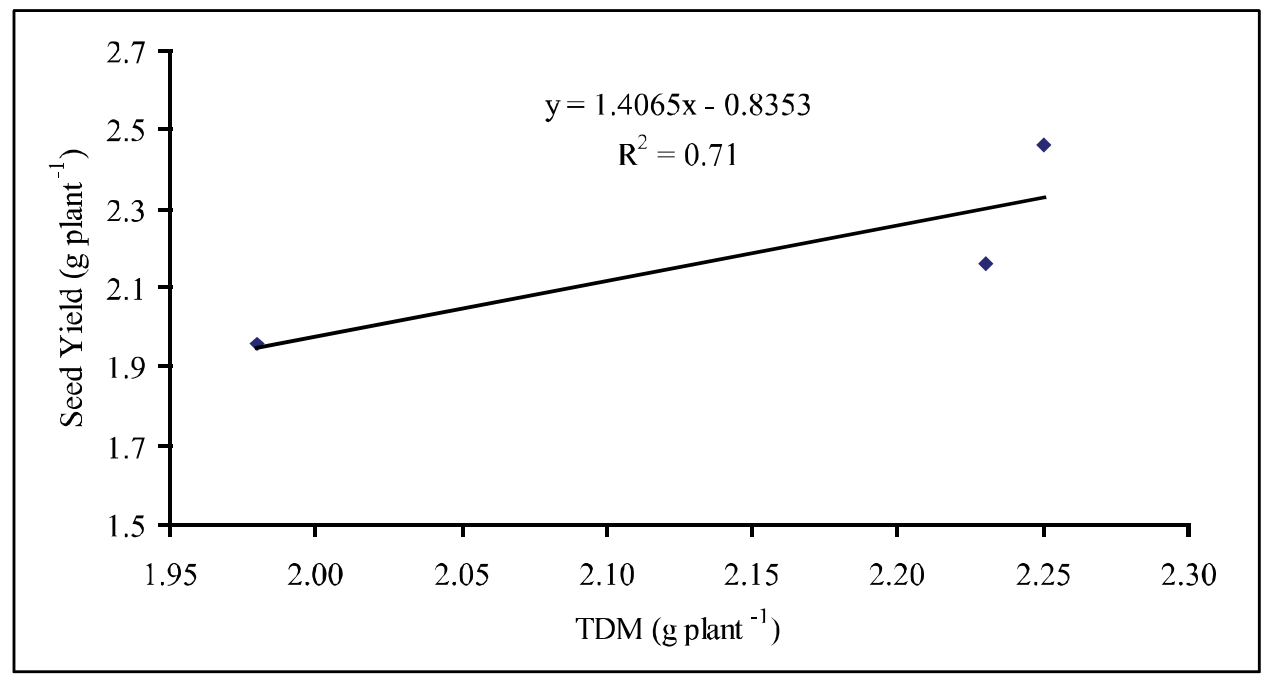

Fig. 2. Functional relationship between TDM and seed yield of mungbean genotypes.

\section{Conclusion}

Soil flooding during pre-flowering stage delayed flowering and maturity of mungbean. Among the five selected mungbean genotypes tested under 4 days waterlogging in field condition and it was observed that plant height, leaves plant ${ }^{1}$, leaf area plant ${ }^{-1}$, total dry matter and yield contributing characters of mungbean reduced to a significant extent when exposed to 4 days flooding. TDM and seed yield was positively correlated. Mungbean genotypes VC-6173A, BU mug 2 and IPSA-13 accumulated the highest TDM. Those genotypes were also produced highest seed yields, larger seed size and less yield reduction relative to control. Therefore, those genotypes seem to be more tolerant to soil flooding under 4 days soil flooding condition. 


\section{References}

Carter, C.E., B. Halverson, J.S. Rogers, and M. Musgrave. 1990. Effects of excess soil water on sweet corn yield. Trans. ASAE 33.1203-1207. In: Evaluating wheat cultivars for waterlogging tolerance. Crop ecology, production and management. Crop Sci. 28: 90-97.

Celik, G. and E. Turhan, 2011. Genotypic variation in growth and physilogical responses of common bean (Phaseolus vulgaris L.) seedlings to flooding. Afr. J. Biotechnol. 10: 7372-7380.

Hamid, A., W. Agata, A. F. M. Moniruzzaman, and A. A. Miah. 1991. Physiological aspects of yield improvement in mungbean. pp. 87-94. In: Proceedings of the Second National Workshop on Pulses, 6-8 Jan, 1989, Joydebpur, Bangladesh.

FAO, 2002. Agriculture. Availableonline.at:http://www.fao.org/waicent/FAOINFO/ AGRICULT/ag1/gaez//nav.html.

Islam, M.R. 2003. Eco-physiology of soil-flooding tolerance in mungbean. A Ph.D. Thesis. Bangabandhu Sheikh Mujibur Rahman Agricultural University. Bangladesh.

Islam, M.R. 2005. Response of mungbean to flooding at vegetative stage I. Root and shoot growth. Bangladesh Agron J. 11(1 \& 2 ):1-9.

Kozlowski, T.T. 1984. Plant responses to flooding. BioScience 34: 162-167. In: Rubio et al. Oecologia (1995) 102:102-105.

Kumar, P., M. Pal, R. Joshi and R. K. Sairam. 2013. Yield, growth and physiological responses of mungbean [Vigna radiata (L.) Wilczek] genotypes to waterlogging at vegetative stage. Physiol, Mol. Biol. Plants. 19(2): 209-220.

Minchin, F. R., R. J. Summerfield, A. R. J. Eaglesham and K. A. Stewart. 1978. Effects of short-term waterlogging on growth and yield of cowpeas (Vigna unguiculata). J. of Agril. Sci. Cambridge. 90: 355-366.

Nawata, E. 1989. Analysis of the responses of yard long bean to waterlogging. A Ph. D. Thesis. Kyoto University, Japan. Pp.1-122.

Parent, C., C. Nicolas, A. Berger, M. Crevecoeur, M.F. Dat. 2008. An overview of plant response to soil waterlogging. Plant stress. Global Science Books. 2(1):20-27.

Pociecha, E., J. Koscielniak and W. Filek. 2008. Effect of root flooding and stage of development on the growth and photosynthesis of field bean (Vicia faba L. Minor). Acta Physiol. Plant. 30: 529-535.

Saha, R.R. 2005. Physiological aspects of yield and seed quality of mungbean. (Vigna radiata (L.) Wilczek). A Ph. D. Thesis. Bangabandhu Sheikh Mujibur Rahman Agricultural University, Gazipur, Bangladesh.

Singh,D. P.and B. B.Singh. 2011. Breeding for tolerance to abiotic stresses in mungbean. J. Food Legumes. 24(2):83-90. 
Suleiman, Z., T. D. Colmer, S. P. Loss, B. D. Thomson and K. H. M. Siddique. 2007. Growth responses of cool-season grain legumes to transient waterlogging. Aust. J. Agric. Res. 58: 406-412.

Umaharan P., R. P. Ariyanayagam and S.Q. Haque. 1997. Effect of short-term waterlogging applied at various growth phases on growth, development and yield in Vigna unguiculata. J. Agril. Sci. Cambridge. Cambridge University Press. 128: 189198.

Voesenek, L. and C. W. P. M. Blom. 1996. Plants and hormones: an ecophysiological view on timing and plasticity. J. Ecol. 84: 111-119.

Williams, R. W., R. J. Lawn, B. C. Imrie and D. E. Byth. 1995. Studies on weather damage in mungbean. Effect of weathering on seed quality and viability. Aust. J. Agric. Res. 46: 887-900. 